\title{
Clinical improvement of patients with emphysema after radiotherapy
}

\author{
A. T. AXFORD, J. E. COTES, T. J. DEELEY, AND C. W. SMITH \\ From the MRC Pneumoconiosis Unit, Llandough Hospital, Penarth, Glam CF6 1XW and South \\ Wales and Gwent Radiotherapy Service, Velindre Hospital, Whitchurch, Cardiff CF5 7XL
}

Axford, A. T., Cotes, J. E., Deeley, T. J., and Smith, C. W. (1977). Thorax, 32, 35-39.

Clinical improvement of patients with emphysema after radiotherapy. In advanced emphysema the reduced lung retractive force permits dynamic compression of the airways during expiration; this gives rise to breathlessness which is often refractory to conventional remedies.

Radiotherapy causes shrinkage of lung tissue and has therefore been given as treatment to 10 patients with emphysema. They have been followed for two years, during which time three have died from various causes, but no adverse effect of radiotherapy has been observed. All the patients at some time experienced a reduction in breathlessness on exertion and an increase in the range of their daily activities; the distensibility of their lungs was on average reduced but the response to test exercise was not altered. The possibility that the clinical improvement may have been a placebo effect is now being investigated.

Patients with chronic airways obstruction may experience improvement following the abandonment of smoking and treatment of infection, reversible airways obstruction or congestive cardiac failure. Compression of the airways by a solitary bullus may be treated surgically. Airways obstruction secondary to diffuse destructive emphysema has in the past been treated in a number of ways, including application of an abdominal binder (emphysema belt), induction of pneumoperitoneum, excision of the cartilages of the first ribs, lobectomy, excision and plication of parts of the lung or lung transplantation. At the present time partial resection offers the best prospect but this is effective for only a small proportion of patients (Abbott et al., 1953; Pride et al., 1970) and reversion is common in those with generalised disease. Shrinkage of the lung may also be achieved by the fibrosis which follows radiotherapy. We observed this in a patient with advanced emphysema who was treated by $x$-ray therapy for an oat-cell carcinoma; he subsequently had a reduction in breathlessness. This prompted us to investigate the effects of irradiation on 10 patients with established emphysema whose breathlessness had not responded to other treatment. The findings over the first two years after irradiation are described in this paper; a pre- liminary account, including a summary of discussion, is contained in the proceedings of the Association of Physicians (Cotes et al., 1975).

\section{Subjects and methods}

The patients all had incapacitating breathlessness with a grossly reduced ventilatory capacity (mean FEV $_{1.0} 0.441$, range $0.2-0.751$ ) and unequivocal clinical, radiographic, and physiological evidence for destructive emphysema including flat diaphragms, increased transradiancy, an enlarged thoracic gas volume, reduced lung recoil pressure, and high compliance. The transfer factor per unit of lung volume (KCO) was greatly reduced, there was moderate hypoxaemia, and the arterial carbon dioxide tension was at the lower end of the normal range.

Three patients (LW, WJF, and HP) had previously been referred for pulmonary resection but this was considered unadvisable on account of either the extent of the disease or the associated disability. The majority of the patients had little chest infection, not much response to bronchodilators, and no history of congestive cardiac failure, but several suffered from reactive depression secondary to hypoxaemia. Three patients 
(OE, RJS, and JM) had experienced episodes of myocardial infarction; one (HTW) had category 1 simple pneumoconiosis of coalworkers. The emphysema was associated with smoking cigarettes (mean consumption 30/day) which all subjects had abandoned or, in two instances (OE and RSJ), reduced to a low level some time before the present treatment (range 6 months to 19 years). In one instance (WJF) there was additional local emphysema at the site of a previous lung abscess. The serum levels of $\alpha_{1}$-antitrypsin were within normal limits. Selection for treatment was made on clinical grounds including failure of conventional treatment and relentless progression of the disease to a stage where life was barely tolerable. The patient, his wife, and general practitioner shared in the decision.

A course of radiotherapy was given to each patient using a 4 million electron volt linear accelerator. Two opposed fields were used, one to the anterior chest and the other to the posterior chest, each of 10 by $10 \mathrm{~cm}$ at the skin surface, the focal skin distance being $100 \mathrm{~cm}$. A total dose of 1600 rads was prescribed, assuming unit density of tissues; this dose was calculated at the centre of the irradiated volume. Treatment was given once weekly to each of the two fields for four weeks, that is, a weekly dose of 400 rads to the volume. Measurements of the exit doses were made using a method previously described (Svarcer et al., 1965) which enabled us to calculate the actual dose received by the centre of the lung irradiated. This was on average about $30 \%$ higher than that obtained assuming unit density of tissues, the range being 1900 rads to 2300 rads with an average 2100 rads and was due to the reduced density of the lung. A second treatment of one or two doses each of $\mathbf{4 0 0}$ rads was given in some instances. The site for irradiation was selected where radioactive isotope studies using aggregated human albumin labelled with iodine-131 suggested that perfusion was absent or greatly reduced. In most instances the ared selected exhibited increased transradiancy and/or bullae, but in one patient (ET) an area was selected which, while poorly perfused, had a relatively low transradiancy.

After the completion of radiotherapy the patients were seen for clinical consultation and, in most instances, for assessment of lung function at four-monthly intervals; however, the actual intervals varied and on several occasions the assessment was made after recovery from an acute chest illness. The measurements of lung function were performed by standard methods which are described elsewhere (Cotes, 1975).

\section{Results}

Radiation was given to one upper zone in six in stances and to a lower zone in four. It gave rise to symptoms in two subjects (DMJ and OE) who developed mild congestive cardiac failure withim eight hours of their first period of irradiation. The failure responded well to conventional remedies and did not recur with subsequent treatment. Ong్ patient (WJF) developed symptoms of chest illnesst on returning from the first of a second course of treatment which was then terminated. Twọ patients (WJF and TWB) at the time of their third irradiation (that is, on the 15th day) commented that their chests did not feel so full and the could take a deeper breath.

Since the completion of treatment the patients have been followed for up to $3 \frac{1}{2}$ years. During this time three patients have developed radiographie evidence of radiation fibrosis and four have died in two instances (LW and OE) from cardiac arrese while in hospital under our care, one (RSJ) from a cerebrovascular accident and one (JM) from protracted chest infection. Three of these patients had a previous history of myocardial infarction At necropsy in the case of LW where irradiatio was given to the right lower zone, there was wide spread centrilobular emphysema of both lower lobes but the right lower lobe was smaller and less distensible than the left and contained an in creased amount of fibrous tissue. In the case of $\mathrm{OE}$, where irradiation was given to the righit upper zone, the right lung was grossly emphyo sematous with cystic changes in the upper lobe The left upper lobe and apical segment of the left lower lobe were also largely destroyed b?. emphysema. In the case of JM, where irradiatio was given to both upper zones there was extensive bilateral emphysema with little evidence of fibrosis.

Immediately before treatment the distance which the subjects could walk was on average $75 \mathrm{~m}$ (range 4-400 m); only one subject (HTW could mount a flight of stairs and all had the beds downstairs on this account; only one (ETE) did not have difficulty in dressing and undressing none could take a bath unaided; and four patients found conversation difficult and laughing impos్ sible on account of breathlessness.

Subsequent to the treatment all the patientS reported that at best they could walk a greatef distance than before treatment, the average pro: portional increase being $550 \%$. Six could moun a flight of stairs and four reverted to using am upstairs bedroom. Three of these men reported 
doing some home painting and paper hanging for the first time for several years. For all patients, washing, dressing, and conversation became less of a problem, and for three patients laughter was no longer impossible. The most dramatic improvements were experienced by WJF, who from having been confined to one room for three years could walk $45 \mathrm{~m}$ up the street to his daughter's house, and by ET, who was able to go to the Chepstow races and resume his part-time voluntary work as an instructor in occupational therapy. The average time interval from the start of treatment to the first recorded improvement was 13 weeks (range 2 weeks to 11 months). The experience of the 10 patients individually is summarised in the Appendix.

The measurements of lung function did not on average show any change during the first six months after treatment. Subsequently (Table) the

Table Mean lung function and changes after radiotherapy

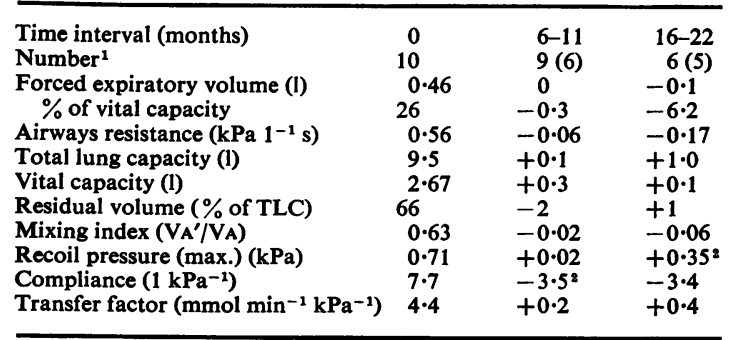

${ }^{1}$ No. for compliance and recoil pressure in parenthesis.

${ }^{2} \mathbf{P}<0.05$.

Conversion: $S I$ to traditional units-Resistance: $1 \mathrm{kPa} 1^{-1} \mathrm{~s} \approx 10 \mathrm{~cm}$ $\mathrm{H}_{2} \mathrm{O}^{-1} \mathrm{~s}$. Pressure: $1 \mathrm{kPa} \approx 7.5 \mathrm{mmHg}$. Compliance: $11 \mathrm{kPa}^{-1} \approx 0.1$

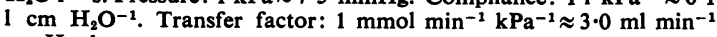
$\mathrm{mmHg}^{-1}$.

static lung compliance was significantly reduced and the recoil pressure of the lung at both total lung capacity and $20 \%$ vital capacity below total lung capacity were increased. There was on average no change in the body weight, ventilatory capacity, lung volumes, transfer factor or physiological response to submaximal exercise; in two patients (HP and ET) the maximal exercise ventilation was increased (Figure).

\section{Discussion}

In patients with chronic airways obstruction, breathlessness is due primarily to a reduced ventilatory capacity. In emphysema, the airways become narrower or obstructed during expiration on

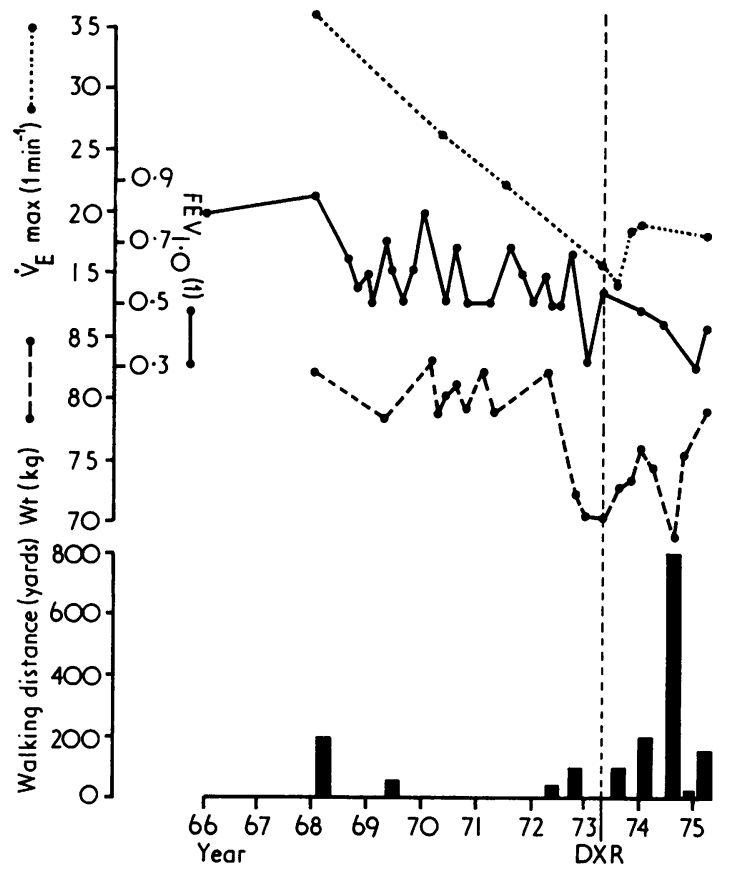

Figure Maximal exercise ventilation $\left(\dot{V}_{E}\right.$ max $)$, forced expiratory volume (FEV 1.0$)$, body weight, and walking distance before and after deep $\mathrm{x}-$ ray therapy $(D X R)$ in the patient $H P$.

account of the depleted lung tissue not exerting sufficient traction to keep them open. This reduction in retractive force due to loss of 'guy lines' may be partly corrected by a reduction in the volume of lung tissue relative to that of the thorax. Shrinkage may be effected by radiotherapy (eg, Deeley, $1960 \mathrm{a}$ and b; Emirgil and Heinemann, 1961), and evidence for its occurrence in the present subjects is available in the increased elastic recoil pressure and reduced lung compliance found on physiological assessment. Thus it is the probable explanation for the diminished breathlessness and increased well-being experienced by our subjects. However, the reduced disability should have been accompanied by a reduction in total lung capacity. This was not observed, possibly on account of a trend in this direction being offset by a material increase in one subject (HP) who nonetheless experienced a useful increase in exercise ability (Figure). Likewise, the increased recoil pressure should have exerted its effect via an increase either in the ventilatory capacity or in the rate of work and/or ventilation attained during maximal exercise. The former did not occur, and the latter was not specifically 
looked for since the exercise procedure was submaximal and directed towards detecting changes in the relationship of ventilation to oxygen uptake and in the pattern of breathing (Cotes, 1972). No such changes were detected. Analysis of the results for the last minute of the progressive exercise test did not indicate any tendency towards an increased maximal oxygen uptake, though an increase in the maximal exercise ventilation occurred in two instances. Thus the physiological findings were not commensurate with the clinical improvement. This may reflect the inadequacy of the tests which can be performed only with difficulty by such disabled subjects. Alternatively, the negative result may be evidence for the clinical improvement being due to other causes, for example, amelioration of airways obstruction due to asthma or bronchitis, or to psychological factors.

The possibility that relief of asthma is responsible for our subjects' clinical improvement is small since none was diagnosed as having asthma and the average increase in forced expiratory volume after administration of bronchodilator drugs was only $11 \%$ (range $0-29 \%$ ).

Chronic bronchitis was present in seven of the 10 patients; this was mainly in winter when almost all of them were confined to the house, but only in the case of JM was bronchitis the main clinical problem. Exacerbation of bronchitis may have delayed the onset of clinical improvement after therapy in the case of ET, and it undoubtedly contributed to the long-term deterioration of some of the other patients. However, our manner of treating chest infections did not change over the period of study, and the results before radiotherapy were obtained during periods of remission; thus the control of chest illnesses is unlikely to have contributed to the clinical improvement. Alternatively, the improvement might be due to the patients responding to the renewed interest and drama associated with the treatment. This seems to us improbable on account of both the slow onset of improvement which was first appreciated by the patients on average three months after the start of treatment and the length of time over which we have observed them both before and after radiotherapy. The question can be resolved only by a controlled trial.

The application of radiotherapy for a condition other than cancer requires justification on account of the treatment possibly hazarding the lung or other organs. The risks include leukaemia or other malignancy, destruction of bone marrow, fibrosis of the heart, radiation pneumonitis and fibrosis, respiratory failure or congestive cardiac failure, and reactivation of infection. However, review of the literature and our own experience suggest that in the dosage used the risks of radiotherapy aresmall in relation to the other hazards to which these patients are already exposed and wholl 9 justifiable if the quality of life can be improved. If is our impression that the improvement is materiaj and of useful duration but this has still to be con- firmed by the double-blind controlled trial whick is now in progress.

We are indebted to Dr. J. C. Gilson for advice and్ encouragement, and to others including Mrs. IAshton, Mrs. C. Bevan, Mr. M. J. Saunders, and Miss E. Kalinowska for the physiological measure? ments, to Dr. J. C. Wagner for the results of thepostmortem examinations, to Miss C. Heywood for help with the analysis, to Dr. J. D. Ball anष Dr. L. Erin for kindly referring patients, and tढ़ Dr. D. A. Williams and Professor P. J. Lindop for helpful suggestions.

\section{Appendix (details of the patients)}

LW Age 51; ht $1.7 \mathrm{~m}$; wt $42 \mathrm{~kg}$; $\mathrm{FEV}_{1.0} 0.21$ From being depressed, confined to one room and too breathless to talk, the patient, after treatmen to RLZ, could move about the house and into the garden, converse, and smile. Death occurred witho out warning two months after completion of treat ment; the recorded causes were congestive cardiag failure, cor pulmonale, and emphysema.

DMJ Age 55; ht 1.77 m; wt $39 \mathrm{~kg} ; \mathrm{FEV}_{1.0} 0.31$ bु After treatment to $L L Z$ could again dress and climb stairs but still needed help with bathing? Gained $10 \mathrm{~kg}$ in weight.

HP Age 58; ht $1.75 \mathrm{~m}$; wt $70 \mathrm{~kg} ; \mathrm{FEV}_{1.0} 0.48 \mathrm{lo}$ After two courses of treatment to the LUZ the walking distance improved from 90 to 750 mo patient could bathe unaided and did some hous decorating. Three years later his exercise abilito had reverted to near the pretreatment level.

HTW Age 70; ht 1.67 m; wt $49 \mathrm{~kg} ; \mathrm{FEV}_{1.0} 0.52 \mathrm{\omega}$ Simple pneumoconiosis category 1 . DXR causeg reduced transradiancy in LUZ. Subsequently afte管 mounting stairs could undress without first pause ing for breath.

WJF Age 51; ht $1.74 \mathrm{~m}$; wt $62 \mathrm{~kg} ; \mathrm{FEV}_{1.0} 0.38$ From being extremely breathless at rest treatmen applied to bullae in RUZ led to patient being able to walk $45 \mathrm{~m}$ down road and sustain conversa 
tions. His consumption of cylinder oxygen was much reduced.

TWB Age 49; ht 1.78 m; wt $61 \mathrm{~kg} ; \mathrm{FEV}_{1 \cdot 0} 0.481$. After treatment to LLZ patient reverted to sleeping upstairs. His walking distance increased from $65 \mathrm{~m}$ to $185 \mathrm{~m}$ and he was able to redecorate his house. A second treatment to the same site did not lead to further improvement and $2 \frac{1}{2}$ years later his exercise ability had deteriorated to the pretreatment level.

OE Age 50; ht 1.72 m; wt $61.5 \mathrm{~kg} ; \mathrm{FEV}_{1.0} 0.751$. Treatment to RUZ led initially to transient fluid retention. Subsequently he could converse and laugh and noted that 'voice vibrates in chest as it used to do'. Walking distance improved from $35 \mathrm{~m}$ to $90 \mathrm{~m}$. Death was recorded as due to ruptured aortic aneurysm, myocardial infarction, and emphysema.

RJS Age 65; ht 1.72 m; wt 49.5 kg; FEV $_{1.0} 0.351$. Treatment to LUZ led to an increase in walking distance from $35 \mathrm{~m}$ to $350 \mathrm{~m}$ and patient reported 'I can now take a deeper breath and when 1 get breathless I recover quicker'. Death eight months later was recorded as due to cerebral infarction, myocardial infarction, and emphysema.

ET Age 65; ht $1.69 \mathrm{~m}$; wt $80 \mathrm{~kg}$; $\mathrm{FEV}_{1.0} 0.531$. Treatment to LLZ was followed by reduced transradiancy and an increase in walking distance from $400 \mathrm{~m}$ to $6500 \mathrm{~m}$. Patient felt much better and abandoned his domiciliary oxygen. All aspects of lung function showed a material improvement.

JM Age 67; ht 1.8 m; wt $82 \mathrm{~kg}$; FEV $_{1.0} 0.371$. Treatment to RUZ led to patient being able to sustain a conversation and to sing, to climb stairs, decorate, and do jobs about the house. 'I feel better than for 10 years and am quite thrilled about it.' Subsequently his condition deteriorated due to recurrent chest infections from which he eventually succumbed two years after the completion of treatment.

\section{References}

Abbott, O. A., Hopkins, W. A., van Fleit, W. E., and Robinson, J. S. (1953). A new approach to pulmonary emphysema. Thorax, 8, 116-132.

Cotes, J. E. (1972). Response to progressive exercise: a three-index test. British Journal of Diseases of the Chest, 66, 169-184.

Cotes, J. E. (1975). Lung Function. Assessment and Application in Medicine, 3rd edition. Blackwell Scientific Publications, Oxford.

Cotes, J. E., Axford, A. T., Deeley, T. J., and Smith, C. W. (1975). Radiotherapy for advanced emphysema. Quarterly Journal of Medicine, 44, 632-633.

Deeley, T. J. (1960a). The effects of radiation on the lungs in the treatment of carcinoma of the bronchus. Clinical Radiology, 11, 33-39.

Deeley, T. J. (1960b). The effects of radiation on the normal lung. In Cancer Progress, Vol. 1960, edited by R. W. Raven, pp. 153-164. Butterworth, London.

Emirgil, C. and Heinemann, H. O. (1961). Effects of irradiation of chest on pulmonary function in man. Journal of Applied Physiology, 16, 331-338.

Pride, N. B., Hugh-Jones, P., O'Brien, E. N., and Smith, L. A. (1970). Changes in lung function following the surgical treatment of bullous emphysema. Quarterly Journal of Medicine, 39, 49-69.

Svarcer, V., Fowler, J. F., and Deeley, T. J. (1965). Exit doses for lung fields measured by lithium fluoride thermoluminescence. British Journal of Radiology, 38, 785-790.

Requests for reprints to: Dr. J. E. Cotes, MRC Pneumoconiosis Unit, Llandough Hospital, Penarth, Glamorgan CF6 1XW. 